\title{
OPTIMIZATION OF THERMAL MODERNIZATION OF A GROUP OF BUILDINGS USING SIMULATION MODELING
}

\author{
Ksenia Olegovna Dubrakova* \\ Southwest State University, Kursk, Russia
}

The paper considers methodological aspects of designing a simulation model to optimize the parameters of thermal modernization of residential buildings on a city scale. We developed an optimization methodology of thermal modernization and tested the sequence of its stages on an arbitrarily chosen group of residential buildings. It was found that, under the chosen design conditions, the proposed optimization methodology could provide additional savings of up to $8.53 \%$. A simple engineering approach to determining the optimal sequence of thermal modernization has been formulated. It is proposed to use an indicator of reduction in thermal energy consumption for heating and ventilation of buildings to explain the procedure for the optimal sequence of stages.

Key words: Thermal modernization, Optimization, Simulation modeling

\section{INTRODUCTION}

When implementing the policy of improving the energy efficiency of existing residential buildings it is quite difficult to find financial resources for heat protection measures.

The studies $[3,8,10,14,15,16,18]$ clearly demonstrate the need for an integrated approach to the implementation of thermal protection works, covering all structural elements of buildings.

Owing to the high resource intensity of the housing and communal services sector, it is necessary to develop a strategy for thermal retrofit of the housing stock in the form of a separate subprogram, which establishes the optimal sequence of thermal modernization of buildings in the selected residential area.

\section{MATERIALS AND METHODS}

When developing a thermal retrofit program in conditions of investment deficit, priorities should be given to the most justified and effective measures, which require successive solutions of the local (first-order) and global (second-order) optimization tasks.

The local optimization problem can be formulated as the search for the most effective combination of the thermal protection parameters of a particular type of building, while ensuring that the level of heat consumption does not exceed the required one. In [7, 9, 12] several different approaches to the solution of this problem, including those proposed by the authors in [4], are described.

The essence of the described problem can be represented in the form of the following expression:

$$
\left\{\begin{array}{l}
\max \Lambda_{j}, \\
q_{\text {desj }} \leq q_{\text {reqj }}
\end{array}\right.
$$

where $\Lambda_{j}$ is net present value (NPV) resulting from the thermal modernization of a residential building of the $j$-th type, MU (monetary unit); $\mathrm{q}_{\mathrm{des}}$ is specific heat consumption of a residential building of the j-th type after thermal modernization, $\mathrm{kJ} /\left(\mathrm{m}^{3} \cdot{ }^{\circ} \mathrm{C} \cdot\right.$ days $) ; \mathrm{q}_{\text {des }}$ is normable specific heat demand of the building of the j-th type, kJ / $\left(\mathrm{m}^{3} \cdot{ }^{\circ} \mathrm{C} \cdot\right.$ days $)$.

To select the optimization parameters of the response function $\Lambda$ let us consider the formula for calculating the NPV, which was proposed by the authors in [5]: where IC is the costs for heat protection measures

$$
N P V=\frac{c_{t 0} \cdot\left(Q_{0}-Q_{1}\right)}{(p-d)} \cdot\left(1-\left(\frac{(1+d)}{(1+p)}\right)^{T_{0}}\right)-I C
$$

expressed in current prices, $\mathrm{MU} ; \mathrm{C}_{\mathrm{t} 0}$ is the current cost of thermal energy unit, $M U / G c a l ; Q_{0}$ and $Q_{1}$ are the consumption of heat energy for heating of the building, before and after the thermal modernization, respectively, Gcal; $p$ is the discount rate in absolute units; $d$ is the average predicted growth factor for heat energy prices in absolute units; $T_{0}$ is the accounting period for the effectiveness evaluation of the thermal modernization program, years.

Expression (2) makes it possible to assess the economic efficiency of the thermal modernization of the selected building starting in the first year, and is completely inappropriate for the buildings that will be modernized several years after the start of the program. Since it is simply impossible to carry out works in all buildings simultaneously, the authors propose an improved formula for buildings that are being modernized after $m$ years from the start of the program [5]:

$$
N P V=\frac{c_{t 0} \cdot\left(Q_{0}-Q_{1}\right)}{(p-d)} \cdot\left(\left(\frac{(1+d)}{(1+p)}\right)^{m}-\left(\frac{(1+d)}{(1+p)}\right)^{m+T_{0}}\right)-I C
$$


Values IC, $\mathrm{C}_{\mathrm{t} 0}, \mathrm{Q}_{0}, \mathrm{p}, \mathrm{d}, \mathrm{T}_{0}$ in the expressions (2) and (3) can not serve as the optimization parameters of the response function, because they are either constant characterizing the initial conditions, or varied independently in accordance with the formulation of the problem. At the same time, the quality of the calculations depends on the objectivity of their values justification.

Thus, the variable values from the considered expression are the heat energy consumption for heating of the building of the type considered after the thermal modernization, $Q_{1}$, Gcal and the year of thermal modernization of the building $\mathrm{m}$ from the start of the program.

Knowing the physical meaning of $Q_{1}$, and also the features of its evaluation detailed in the normative literature one can write down:

$$
Q_{1}=f\left(X_{1}, X_{2}, X_{3}, X_{4}, X_{5}, X_{6}\right)
$$

Denoting the optimal value of the NPV for the building of the j-th type in the i-th year as $\Lambda_{\mathrm{ij}}$, we write that $\Lambda_{i}=\mathrm{f}\left(Q_{1}, \mathrm{~m}\right)$. Then the parameters given in expression (4), together with $\mathrm{m}$, are adopted as optimization functions for the objective function $\Lambda_{\text {ij, }}$, and are written as follows:

- type of additional insulation for external walls (factor $\mathrm{X}_{1}$ );

- thickness of additional insulation layer of external walls $\delta_{\text {wall }}^{\text {ad }}\left(\right.$ factor $X_{2}$ ), m;

- resistance to heat transfer of newly installed window and balcony fillings of the building under thermal modernization $\mathrm{R}_{\text {win }}$ new (factor $\mathrm{X}_{3}$ );

- type of layer material for additional thermal insulation attic floor (factor $\mathrm{X}_{4}$ );

- thickness of the layer of additional insulation of the attic floor $\delta_{\text {attic }}^{\text {ad }}\left(\right.$ factor $X_{5}$ ), $m$;

- thickness of the layer of additional thermal insulation of flooring on the ground floor $\delta_{\text {floor }}$ ad $\left(\right.$ factor $\left.X_{6}\right), m$.

- the year of thermal modernization of a residential building of a certain type from the start of the program implementation $\mathrm{m}$ (factor $\mathrm{X}_{7}$ ), year.

It is expedient to use mathematical models for the implementation of the initial approach to optimization. In this case the determination of the values of the objective function is performed by calculating the values of the output parameters, which are functionals of the system phase coordinates. In this case, there are no analytical expressions that establish a direct relation between the controlled parameters and the function, which excludes the direct use of the expressions for the derivative, etc., for the determination of extremes. Search engine optimization can be used to solve the final problem. Its essence lies in the fact that the search for an extreme point in the space of controllable parameters is carried out by successive steps to a full view of the factor space.

The planning of the optimal thermal modernization of the housing stock in a residential area involves finding the parameters determining the choice of such types and the number of residential buildings, and also determining the sequence of their thermal modernization (with the optimal level of thermal protection for each selected building) over the years of the program implementation period to ensure the highest economic efficiency of the thermal modernization program, which can be described by the expression:

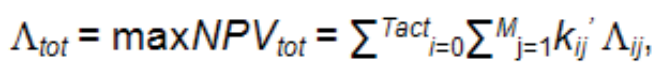

where $\mathrm{L}_{\text {tot }}$ or NPV $\mathrm{V}_{\text {tot }}$ is the maximum total net present value resulting from the implementation of the thermal modernization program by the end of the period, $\mathrm{MU}$; $\mathrm{k}_{\mathrm{ij}}$ ' is the number of thermo-modernized buildings of the j-th typoe for the i-th year, pcs; $\wedge_{\mathrm{ij}}$ is optimal NPV for the building of the j-th type for the i-th year determined in the course of solving the local optimization problem, $M U ; \mathrm{T}_{\text {act }}$ is the period of the active phase of thermal modernization during which the implementation of heat protection measures is taken in the buildings under consideration, year.

To solve the formulated problem, it is necessary to specify additional five initial parameters. Their justification in the solution of the problem of planning thermal modernization is a fairly important stage in the preparation of the initial data.

The first initial parameter is the number of thermo-modernized buildings ( $N$, pcs) in the residential area under consideration.

The second parameter is the number of types of buildings ( $\mathrm{M}, \mathrm{pcs})$.

The third parameter is the number of houses of each type $\left(k_{1}, k_{2} \ldots k_{M}\right)$, the sum of which is equal to the total number of buildings, i.e. $\sum \mathrm{k}_{\mathrm{j}}=\mathrm{N}$.

The fourth parameter is the active time of the realization of the thermal modernization project in the residential area, $\left(T_{\text {act }}\right.$, years). When justifying it, one should first of all proceed from the possibility of an objective forecasting of changes in the norms of energy-efficient heat consumption, as well as the real capabilities of construction contractors and the amount of financing for the program. The fifth initial parameter is the intensity of the program of thermal modernization $\eta_{i}=f(t)$, characterizing the distribution of the number of reduced equivalent volume elements of thermo-modernized buildings by the years of the active phase of the implementation of works. For the i-th year, the intensity is given by:

$$
\eta_{i}=\sum^{M_{j=1}} \varphi_{j} k_{i j}
$$

where $\varphi \mathrm{j}$ is the correction coefficient of the equivalence of a volume element for the j-th type of buildings, which in turn is determined by the expression $\varphi_{j}=V_{i} / V_{\text {min }}$, where $V_{j}$ is the volume of the heated part of the $j$-th type of buildings, $\mathrm{m}^{3} ; \mathrm{V}_{\min }$ is the minimum volume of the heated part in the selected types of buildings, $\mathrm{m}^{3}$.

The need to introduce the concept of the number of reduced equivalent volume elements, rather than a simple number of buildings, is due to the objective of obtaining comparable results, on the one hand, and on the other hand, it is due to the need to ensure a reliable distribution 
of the volumes of the works to be performed in accordance with the accepted intensity.

The generalized algorithm for evaluating the effectiveness of the thermal modernization program of the housing stock under the initial above-mentioned parameters is presented in the form of a block diagram in Figure 1.

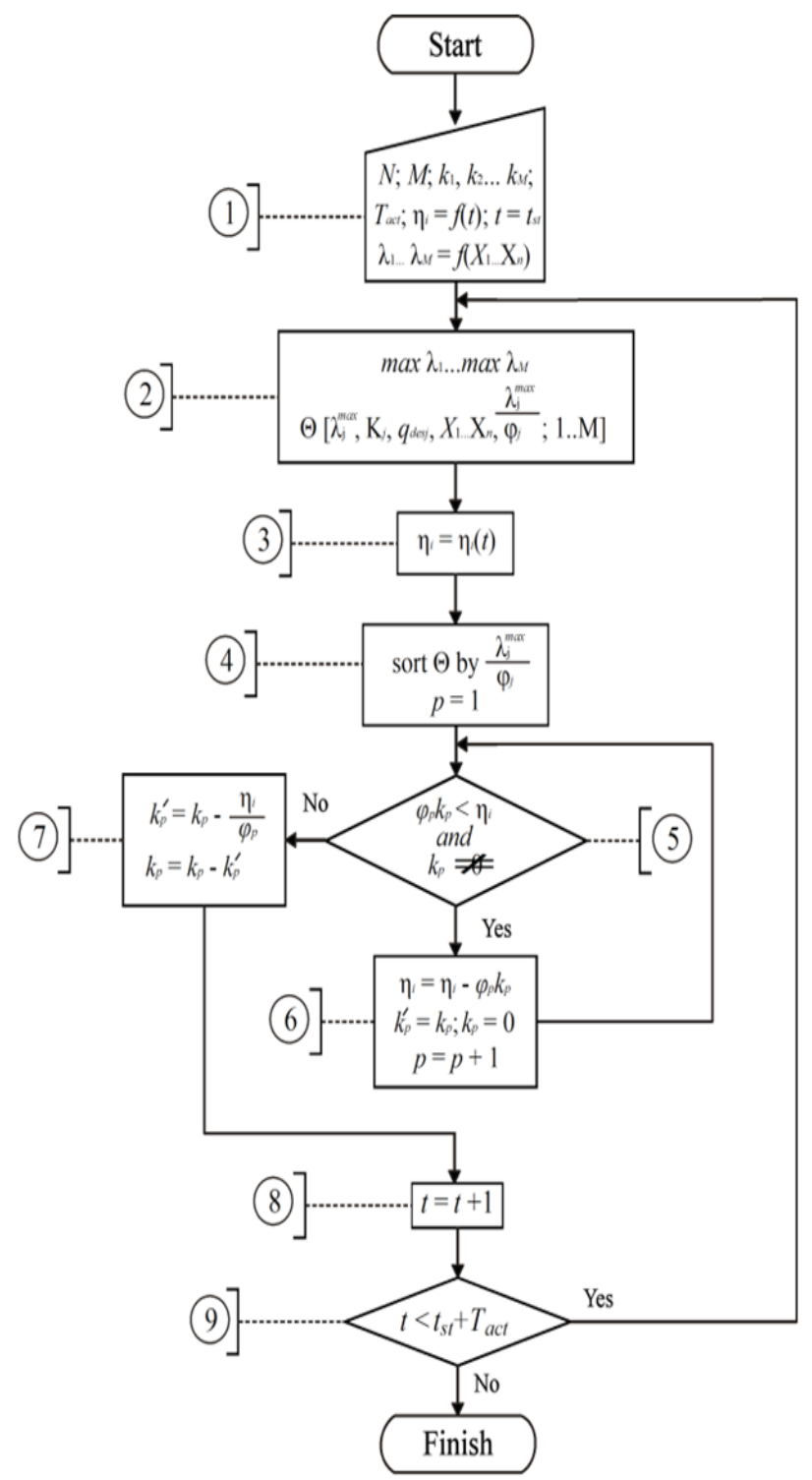

Figure 1: Generalized algorithm for evaluating the effectiveness of the thermal modernization program of the housing stock under the initial parameters

This algorithm can be represented in the form of the following sequential cyclic steps:

1. the initial parameters $N ; M ; k_{1}, k_{2} \ldots k_{M} ; T_{\text {act }}, \eta_{i}(t)$ and NPV models $\lambda_{1} \ldots \lambda_{M}=f\left(X_{1} \ldots X_{n}\right)$ for each type of building are entered, with the time argument $t$ given a the initial value $t_{s t}$;

2. for the current time the problem of local optimization of the thermal modernization parameters for each type of buildings is solved, and a two-dimensional vector $\Theta$ is constructed;

3. taking into account the assumed trajectory, the value of the thermal modernization intensity for the current step $\mathrm{t}$ is calculated;

4. the values of the vector $\Theta$ are sorted by the criterion $\lambda_{j} / \varphi_{j}$. If $\lambda_{j}$ increases with the time of the active phase, sorting is done in the ascending order, otherwise - in the descending order. After this, the index variable $p$ of the vector $\Theta$ is assigned an initial value 1;

5. if the number of building types with the index $p$ differs from zero, the total number of equivalent volumes is compared with the value of the thermal modernization rate $\eta_{i}$ for the current step $t$;

6. the intensity value or its remainder for the current step $t$ is reduced by the total number of equivalent volumes of this type of buildings with the index p; the variable quantity of this type of buildings with the index $p$ that are thermo-modernized at the current step $t$ is assigned their remaining number and their total number is reset to zero so as to exclude this type of building from further consideration; the index variable $p$ increases by 1 .

7. the variable of the number of buildings with the index $p$ that are thermo-modernized at the current step $t$ is assigned the difference between their total number and the ratio of the sum or the residual intensity to the correction factor of an equivalent volume element for a given type of buildings with the index $\mathrm{p}$;

8. the value of the calculated step (in this case 1 year) is added to the time argument $\mathrm{t}$;

9. the time argument $t$ is compared with the end time of the active phase of thermal modernization.

The task of optimization in simulation modeling differs significantly from optimization in traditional mathematical modeling. The simulation model is built outside the framework of the optimization process with the maximization or minimization of the objective function. The optimization process within the simulation model is implemented by systematic changing the values of the controlled variables and then obtaining the results of the model run. The specificity of this kind of simulation is that the results reach steady values only after multiple repetition of the experiment.

As in each experiment, the observations should be statistically independent and equally distributed in the simulation, so that the correct statistical interpretation of the simulated system is ensured [11]. The principal issue is the choice of the number of repeated observations. In the simulation, the results are usually unstable in the first stage (transition state), stability (stationarity) is achieved under a sufficiently long run of the model. Then the sample error measured by the mean square deviation decreases and, consequently, the results become more accurate.

Using different sequences of random numbers ensures the independence of observations and reduces the sample error.

Despite the implementation of the above-described pro- 
cedure for reducing the sample error, the trial runs of the model showed that the achievement of the stationary state takes a lot of computer time, on the one hand, and there is difficulty in determining the transition to a stationary mode, on the other hand.

To determine accurately whether a stationary state is reached, one of the methods of interrupting procedures the repetition method is used [11]; in this method the duration of the initial modeling period ending before the observation begins is recorded.

When using the repetition method, each observation is obtained by a separate run of the model, with all runs starting with the same initial conditions, but using different sequences of random numbers. When stationary states are reached, observations $y_{1}, y_{2}, y_{3} \ldots y_{n}$ are obtained in the form of values of net present values. The best estimate of this characteristic was calculated as the average value of the individual runs for the accepted simulation conditions:

$$
\bar{Y}=\frac{1}{n} \sum_{i=1}^{n} Y_{i}
$$

Their variances were also calculated by the formulas:

$$
S_{i}^{2}=\frac{1}{n-1} \sum_{i=1}^{n}\left(Y_{i}-\bar{Y}\right)^{2},
$$

whereiis the numberofrun; nistheamountofruns. Theexact value of the mean with a reliability of $95 \%$ was calculated as

$$
\bar{Y}-t_{y ; n}\left(\mathrm{~S} / n^{1 / 2}\right)<Y<\bar{Y}+t_{y ; n}\left(\mathrm{~S} / n^{1 / 2}\right)
$$

where $\bar{Y}$ is the average value of the maximum net present value; $S$ is mean square deviation; $n$ is the amount of runs; $t_{\mathrm{\gamma} ; \mathrm{n}}$ is $\mathrm{t}$-statistic for the probability level $\mathrm{y}=0,05$.

The resulted statistical characteristics allowed formalizing the modeling process and reducing the computer time required for runs.

The implementation of the thermal modernization program according to the proposed procedure made it possible to achieve the maximum net present value in the selected housing stock.

\section{RESULTS}

The proposed methodology was used for the optimization of the sequence of the thermal modernization stages for a group of 720 residential buildings, which were represented by 12 typical series and included 60 buildings of each type. The climatic conditions were characterized by the HSDD value of $4763.7^{\circ} \mathrm{K}$ per day. The economic conditions for the implementation of the planned program of thermal modernization were characterized by a discount rate of $10 \%$, a growth rate of tariffs for thermal energy of $15 \%$ per year and a current tariff of 45 USD/ Gcal.
It was assumed in the calculations that the active phase of the thermal modernization program would last for 12 years. It was assumed that the same number of equivalent volumes of buildings, equal to $231.70 \mathrm{EQ}$ units/year would be modernized within 12 years.

Based on the results of calculations, a graph of the optimal sequence option (Figure 2), ensuring the maximum economic effect in the form of total NPV for the entire duration of heat protection measures in the amount of $2,425,128,063$ USD was constructed. The graph has the form of a histogram, the columns of which show the number of buildings modernized in each year out of 12 years of the active phase of the program. The colors and figures in individual sections of the columns show the types of buildings in question and their number.

Estimating the calculated value of the NPV for the optimal sequence of thermal modernization stages for the considered group of residential buildings, it should be noted that, on the one hand, an impressive figure has been obtained, and on the other hand, it must be remembered that it will take 50 years to achieve this result; and for the implementation of such a program it is necessary to spend $662,402,316$ USD over 12 years and to modernize almost 15 million cubic meters of the existing residential buildings. With such big volumes, it is important to make sure that the proposed strategy is effective and expedient, and justify it thoroughly by scientific methods. To formulate reliable conclusions, the calculations of the two alternative options for the sequence of thermal modernization stages for the group of residential buildings that are close to the optimum have been additionally carried out. Alternative options provided an economic effect in the form of the total NPV for the entire duration of thermal protection measures of $\$ 2,423,552,546$ (option 2) and $\$ 2,407,198,675$ (option 3), respectively.

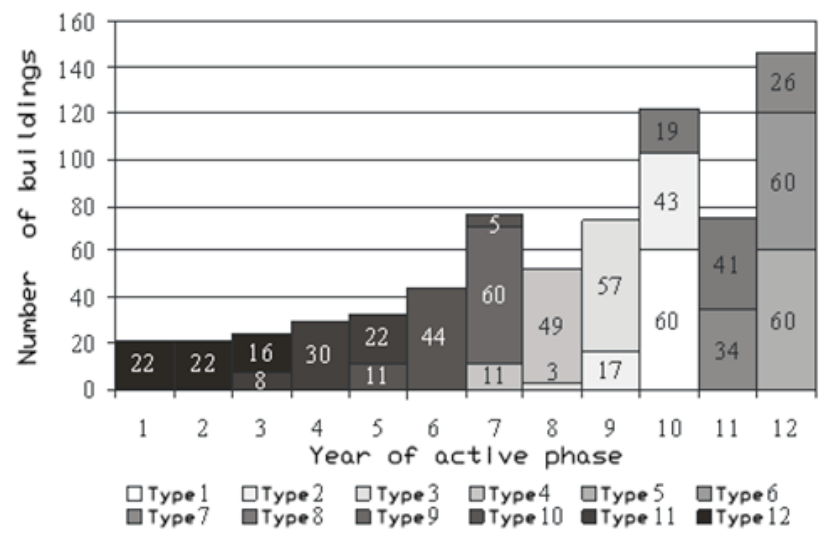

Figure 2: Optimal sequence of thermal modernization stages for the group of residential buildings under consideration

For the confrontation of the conclusions, an option of the thermal modernization sequence for the selected buildings with the least economic efficiency (option 4) was also used, with the NPV in the amount of 2,234,474,213 USD. For all these options, the graphs were construct- 
ed in the form of histograms showing the distribution of types and number of thermo-modernized buildings by years.

Analyzing the values of the NPV and the constructed graphs, it was found out that the sequence of thermal modernization for the selected group of residential buildings significantly affected its effectiveness. The difference between the maximum and minimum values of the NPV, which characterizes, respectively, the optimal and least economical options of the thermal modernization sequence for the buildings under consideration (without changing other parameters) was measured by $190,653,850$ USD, which was comparable to the budget of a large city. Thus, this difference was $8.53 \%$ relative to the minimum value of the NPV.

\section{DISCUSSION}

The logical final step in the analysis was the establishment of regularities in the distribution of buildings by the years of the active phase of program implementation, i.e. regularities of the formation of the sequence of thermal modernization of buildings.

In order to explain the regularities of the sequence related to the choice of building types by years of their thermal modernization, the indicator of reduction in thermal energy consumption for heating and ventilation of building $\Delta \mathrm{q}_{\text {heat }}$ is used; it is numerically equal to the difference in the values of the given characteristic for the chosen building type before $\left(q_{\text {heat }}\right.$ bf $)$ and after $\left(q_{\text {heat }}\right.$ af $)$ its thermal modernization:

$$
\Delta q_{\text {heatt }}=q_{\text {heat }} \text { bf }-q_{\text {heat }}^{\text {af }} .
$$

The physical explanation of the revealed regularity can be given for the building types if, firstly, it is taken into account that buildings of the type in question have almost the same heat-shielding qualities of external enclosures, and the cost of their thermal modernization differs insignificantly with reference to the volume.

Secondly, it is quite logical to assume that the smaller the amount of thermal energy is saved during thermal modernization, i.e. the smaller the value of the index $\Delta q_{\text {heat }}$ for the chosen type of building is, the smaller economic efficiency is achieved by the measures taken in a given period of time in comparison with the types of buildings with a higher $\Delta q_{\text {heat }}$

Thirdly, it is necessary to take into account that for the assumed economic conditions with time the value of the NPV resulting from the thermal modernization of even the same type of building is growing. Consequently, the later the modernization of the building type ensuring a higher reduction in the heat loss is made, the greater will be its contribution to the total value of the NPV resulted from the implementation of the program. In our case, this influenced the formation of the thermal modernization sequence for the group of buildings under consideration. Thus, it has been revealed that when implementing multi- year thermal modernization programs for large groups of buildings, it is expedient to start this program with the types of buildings with the lowest value of reduction in thermal energy consumption for heating and ventilation of buildings. This will maximize the efficiency of the measures taken and ensure the greatest economic effect for the entire program.

\section{REFERENCES}

1. Bolotin, S.A. Model of space-time analogy in optimizing the sequence of objects being reconstructed / S.A. Bolotin, A.Kh. Dadar, M.A. Kotovskaya // Engineering and Construction Journal. - 2013. - № 7. - p. 51-57.

2. Gagarin, V.G. Macroeconomic aspects of justifying energy-saving measures while increasing the thermal protection of building envelopes / V.G. Gagarin // Construction materials. - 2010. - № 3. - p. 8-16.

3. Yezersky, V.A. The influence of the parameters of thermal protection of a building on the specific consumption of thermal energy / V.A. Yezersky, P.V. Monastyrev, R.Yu. Klychnikov // Housing construction. - 2010. - №1. - p. 43-45.

4. Yezersky, V.A. Optimization of parameters of thermal protection of a building according to economic criteria / V.A. Yezersky, P.V. Monastyrev, R.Yu. Klychnikov // Industrial and civil construction. - 2010. - №3. - pp. 13-16.

5. Yezersky, V.A. Features of the economic assessment of thermal modernization of buildings in the conditions of modern market relations / V.A. Yezersky, P.V. Monastyrev, R.Yu. Klychnikov // Housing construction. - 2010. - №8. - p. 9-12.

6. Klychnikov R. J., Monastyrev P. V., Yezerskiy V. A. 2014 CRC - City Retrofit Calculation. Certificate for computer program No. 2014616197. Registered in the Computer Programs Register June 16, 2014.

7. Kozlov, V.V. Fundamentals of optimization of thermal protection of enclosing structures for the recoupment of energy-saving measures / V.V. Kozlov // Construction materials. - 2013. - № 6. - p. 10-13.

8. Samarin, OD Thermophysics. Energy saving. Energy Efficiency / OD Samarin // Monograph. Publishing MGSU. - 2009. - p. 292.

9. Samarin, OD The choice of the optimal combination of energy-saving measures in the reconstruction of buildings of educational institutions / OD. Samarin // Housing construction. - 2015. - №2. - p. 25-7.

10. Tabunshchikov, Yu.A. Ways to improve the energy efficiency of buildings in use / Yu.A. Tabunshchikov, V.I. Livchak, V.G. Gagarin, N.V. Shilkin // AVOK: Ventilation, heating, air conditioning, heat supply, and building thermal physics. - 2009. - № 5. 
11. Taha, H. A. Operations Research: An Introduction. // Per. from English - M : Publishing house "Person", 2010. - 912 p.

12. Sheina, S.G. Problems, prospects and development dynamics of low-rise construction in Russia, the Rostov region / S.G. Sheina, E.N. Minenko, M.V. Smogrunova, S.I. Sheka // New technologies. - 2012. - № 4. P. 152-158.

13. Sheina, S.G. Methods of selection of organizational and technological resource-saving solutions in housing construction according to a multi-criteria evaluation system / S.G. Sheina, E.N. Minenko // New technologies. - 2016. - № 6. P. 42-45.

14. Thermal conductivity of mineral wool plates under operating conditions /B.V. Gusev, V.A. Yezersky, P.V. Monastyrev Industrial and civil construction. - 2005. - № 1. S. 48-49.

15. Gusev, B.V. Changes in the linear dimensions of mineral wool plates under operating conditions / B.V. Gusev, V.A. Yezersky, P.V. Monastyrev //Industrial and civil engineering. - 2004. - № 8. S. 32-34.
16. Erofeev, A.V. Decorative and protective plates for facade finishing of buildings /A.V. Erofeev, V.P. Yartsev, P.V. Monastyrev.Proceedings of higher educational institutions. Technology textile industry. - 2017. - № 1 (367). Pp. 101-104.

17. Travush, V.I. Experimental and theoretical study of the strength and stability of compressed wood rods under power and environmental impact / V.I. Travush, V.I. Kolchunov, K.O. Dmitriev // Proceedings of higher educational institutions. Technology textile industry. - 2016. - №3. Pp. 280-285.

18. Tomakov, I. V., Tomakov, V. M., Pahomova, G. E., Semicheva, E. N., \& Bredihina, V. N. [2018]. A study on the causes and consequences of accidents with cranes for lifting and moving loads in industrial plants and construction sites of the Russian Federation. Journal of Applied Engineering Science, 16(1), 95-98. 